\title{
Problema de Pesquisa: Análise dos Artigos Científicos Publicados no 22 Congresso Brasileiro de Custos
}

\author{
Denize Cavichioli \\ Mestrado em Contabilidade pela Universidade Estadual do Oeste do Paraná - \\ UNIOESTE \\ Professora da Pontifícia Universidade Católica do Paraná - PUCPR \\ Avenida União, 500. Jardim Coopagro. Toledo/PR. Brasil. CEP: 85.902-532 \\ E-mail: denize-gcu@hotmail.com
}

\section{RESUMO}

O objetivo do presente estudo é verificar como foram elaborados e apresentados os problemas de pesquisa dos artigos científicos publicados no $22^{\circ}$ Congresso Brasileiro de Custos e a relação entre o número de autores e os problemas por eles apresentados. Os principais pontos teóricos abordados foram a formulação e delimitação de um problema de pesquisa e suas possíveis incoerências. A pesquisa caracteriza-se: quanto ao objetivo, como descritiva; quanto à abordagem do problema, como quantitativa-quantitativa; e, em relação aos procedimentos, é tida como uma pesquisa bibliográfica. Para cumprir com o objetivo, foram levantados todos os artigos dos Anais do 22.. Congresso Brasileiro de Custos e analisados seus problemas de pesquisa. Como principais resultados, identificou-se que 51 artigos não expuseram problemas de pesquisa, e dos que não apresentaram de forma explícita os problemas de pesquisa, o maior número foi identificado na área temática Custos como Ferramenta para o Planejamento, Controle e Apoio a Decisões, constituindo 35,30\%. Além disso, foram identificados 7 artigos com problemas de "engenharia" em seu problema e nenhum com juízo de valor; 4 problemas não se apresentam de forma interrogativa, e 18 problemas são possíveis de se responder com "sim" ou "não". Não foi verificada relação entre o número de autores e a qualidade dos artigos produzidos. Concluiu-se, de forma geral, que houve pouco rigor na elaboração e apresentação dos problemas de pesquisa dos artigos científicos publicados no $22^{\circ}$ Congresso Brasileiro de Custos. Como contribuição teórica do estudo, destaca-se a apresentação de incoerências em problemas de pesquisa, que podem ser evitados e que comprometem a qualidade de uma pesquisa. Tratando-se de contribuição acadêmica, buscou-se investigar qual o impacto que o número de autores têm na qualidade dos problemas de pesquisa.

Palavras-chave: Problema. Pesquisa Científica. CBC.

\section{Research Problem: Analysis of Scientific Papers Published in the 22nd Brazilian Congress of Costs}




\section{ABSTRACT}

The objective of this study is to verify how the research problems of the scientific articles published in the 22nd Brazilian Congress of Costs were elaborated and presented and it also aims to show the relationship between the number of authors and the problems they presented. The main theoretical points described were the formulation and delimitation of a research problem and its possible inconsistencies. This research is characterized: a descriptive objective; a quantitative-quantitative approach problem; and, a bibliographical procedure. In order to achieve the objective, there were analyzed all research problems from the articles of the 22nd Brazilian Congress of Costs. The main results indicate that 51 articles did not present research problems, and from those that research problems were not identified, the largest number was observed in the area of Costs as a Tool for Planning, Control and Decision Support, representing $35.30 \%$. In addition, 7 articles showed "engineering" problems in their research problem and none of them had value judgment; 4 problems are not present in an interrogative form, and 18 problems can be answered with "yes" or "no". There was not found any relation between the number of authors and the quality of the articles. In conclusion, the research problems from the scientific articles published in the 22nd Brazilian Congress of Costs show little rigor in the elaboration and presentation aspects. As a theoretical contribution of the study, we highlight the presentation of some inconsistencies in the research problems that can be avoided and that compromise the quality of a research. As an academic contribution, we sought to investigate the impact that the number of authors have on the quality of research problems.

Keywords: Problem. Scientific research. CBC.

\section{INTRODUÇÃO}

A Ciência se desenvolve por meio da realização de pesquisas científicas. A pesquisa científica, por sua vez, conforme destacam Nascimento, Aragão, Gomes e Nova (2013), constitui-se em uma ferramenta indispensável para a promoção e avanço da ciência, caracterizando a busca por novas descobertas e incentivo a reflexões. Os autores destacam ainda que a pesquisa exige esforço, principalmente mental, mas, em contrapartida, é capaz de impulsionar a compreensão ao invés de memorização, a investigação, o senso crítico e o progresso ao invés da estagnação.

Nesse contexto, vale ressaltar que uma pesquisa científica precisa ser produzida com qualidade para que possa alcançar esses objetivos relativos à promoção do 
conhecimento. E, para o alcance do êxito dessa qualidade, destaca-se o problema de pesquisa, que é um elemento crucial em seu desenvolvimento.

O problema de uma pesquisa científica constitui-se em expressar, de forma explícita, clara, compreensível e operacional, qual a dificuldade com a qual nos defrontamos e que pretendemos resolver, sendo que sua formulação tem por objetivo torná-lo individualizado e específico (Gomides, 2002). A problematização de um trabalho científico ocorre após a delimitação e tematização do assunto a ser pesquisado, sendo sua descrição essencial para aclarar o objeto de pesquisa que o estudante pretende investigar (Beuren, 2012).

O que ocorre é que, em muitas pesquisas realizadas, não são observados requisitos mínimos para a elaboração do problema de pesquisa. Nesse sentido, Cunha, Dal Magro e Dias (2012) ressaltam que, se as questões de pesquisas não forem colocadas de forma correta, a probabilidade de que sejam geradas teorias interessantes e significativas diminuem.

Pesquisadores têm explorado a temática do problema de pesquisa, entre eles Cunha et al. (2012) e Silva, Araújo, Zuccolotto e Pinto (2013). Cunha et al. (2012) identificaram a qualidade dos problemas de pesquisa nos artigos científicos publicados no 11.. Congresso USP de Controladoria e Contabilidade. Em outro estudo, Silva et al. (2013) analisaram a similaridade das características epistemológicas do problema, objetivos e hipóteses de artigos dos congressos USP e EnANPAD.

Orientado pela motivação de estudar o problema da pesquisa científica, eis que surge a questão de pesquisa: Como foram elaborados e apresentados os problemas de pesquisa dos artigos científicos publicados no $22^{\circ}$ Congresso Brasileiro de Custos e qual a relação entre o número de autores e os problemas por eles apresentados? Buscando responder a questão, o estudo tem por objetivo geral verificar como foram elaborados e apresentados os problemas de pesquisa dos artigos científicos publicados no $22^{\circ}$ Congresso Brasileiro de Custos e a relação entre o número de autores e os problemas por eles apresentados.

O estudo justifica-se devido à peculiaridade em se estudar elementos que são essenciais para a qualidade da pesquisa e pelo fato de que constantemente o problema 
de pesquisa, que compreende um desses elementos essenciais, é elaborado sem ter a prudência necessária pela importância que apresenta. Sob a perspectiva teórica, o estudo justifica-se por acrescentar resultados a estudos sobre problemas de pesquisa. Sob a perspectiva acadêmica, busca-se investigar qual o impacto que o número de autores tem na qualidade dos problemas de pesquisa. Ainda, justifica-se a escolha dos artigos científicos publicados no Congresso Brasileiro de Custos pela relevância que o mesmo possui no meio acadêmico, especialmente na área de Contabilidade, sendo o principal evento ligado à área de Custos empresariais do Brasil e o principal divulgador da produção técnico-científica da especialidade e áreas afins (CBC, 2017).

O estudo é composto por cinco seções, iniciando com esta seção introdutória. $\mathrm{Na}$ seção seguinte, é exposta uma revisão teórica sobre o problema de pesquisa. A terceira seção faz uma explanação do delineamento metodológico utilizado na pesquisa. Os resultados obtidos e sua análise são abordados na quarta seção. Por fim, na quinta seção, são apresentadas as considerações finais, bem como a resposta para a pergunta de pesquisa e recomendações para futuras pesquisas.

\section{REFERENCIAL TEÓRICO}

Com o intuito de aprofundar as reflexões sobre o tema analisado, nesta seção são abordadas a formulação e delimitação do problema de pesquisa científica, bem como incoerências possíveis em um problema de pesquisa.

\subsection{Formulação e Delimitação de um Problema de Pesquisa}

Formular um problema não é um procedimento simples. Sua elaboração envolve uma série de variáveis que não podem, na maioria das vezes, ser controladas; é o caso do fator criatividade (Gomides, 2002). O processo de investigação começa com um problema, que é uma situação real ou artificial, perplexa ou desafiadora, que exige reflexões para sua solução (Gressler, 2003).

Gressler (2003) assevera que, muitas vezes, o pesquisador possui uma dúvida bastante geral, vaga, desordenada e, até mesmo, confusa sobre o que planeja 
investigar, o que faz com que haja dificuldades na formulação clara e operacional do enunciado, mesmo tendo identificado o problema. Um problema de pesquisa é um enigma intelectual que o pesquisador quer investigar, cuja declaração normalmente consistirá em alguns parágrafos concisos que podem fazer referências a algumas publicações, como relatórios de pesquisas anteriores e áreas relacionadas, tanto acadêmicas quanto não acadêmicas, discussões teóricas, estatísticas oficiais e, talvez, artigos de jornal (Blaikie, 2009).

Johnson e Christensen (2008) diferenciam a elaboração do problema em pesquisas quantitativas e qualitativas, enfatizando que, na pesquisa quantitativa, a ênfase se dá sobre a necessidade de explicar, prever ou descrever algum resultado ou evento, enquanto que, na qualitativa, o problema da pesquisa concentra-se em explorar algum processo, evento ou fenômeno. A formulação do problema, conforme afirmam Marconi e Lakatos (2013), está diretamente relacionada com o tema proposto, esclarecendo a dificuldade específica com a qual se depara e que pretende solucionar por meio da pesquisa. De acordo com as autoras, o problema deve atender as seguintes questões:

a) O problema pode ser enunciado em forma de pergunta?

b) Corresponde a interesses pessoais (capacidade), sociais e científicos, ou seja, de conteúdo e metodológicos? Esses interesses estão harmonizados?

c) Constitui-se o problema em questão científica, ou seja, relacionam-se entre si pelo menos duas variáveis?

d) Pode ser objeto de investigação sistemática, controlada e crítica?

e) Pode ser empiricamente verificado em suas consequências?

Richardson (2010) assevera que o pesquisador formula o problema que planeja estudar depois de refletir sobre sua experiência e colocá-la no seu trabalho. O autor ressalta ainda que o problema é formulado em termos de pergunta, podendo ser iniciado com as expressões "qual", "quê", "quando" e "como".

Nesse sentido, Gressler (2003) apresenta as características que um problema precisa ter, as quais podem ser visualizadas no Quadro 1. 


\begin{tabular}{l}
\hline a) O problema deve refletir ou estabelecer a relação entre duas ou mais variáveis; \\
\hline b) O problema deve ser formulado em forma de questão, para a qual se busca uma reposta; \\
\hline c) O problema deve ser formulado de maneira clara, objetiva e resumida, a fim de que o \\
pesquisador possa avançar em sua tarefa de operacionalizar a investigação; \\
\hline d) O problema deve relacionar-se harmonicamente com as demais partes do projeto de \\
pesquisa: com as hipóteses, instrumentos, fundamentação, etc.; \\
\hline e) O problema deve demonstrar que é passível de verificação científica; \\
\hline f) O problema deve ser uma indagação para a qual se busca uma ou diversas respostas; um \\
problema deve referir-se a "O que acontece quando", "Qual a causa de", "Como deveria ser... \\
para"; \\
\hline g) O problema deve ser passível de comprovação científica.
\end{tabular}

\section{Quadro 1. Características do Problema}

Fonte: Adaptado de Gressler (2003).

Delimitar o problema de pesquisa é uma tarefa que exige maturidade por parte do pesquisador. De acordo com Castro (2006), em uma determinada área de investigação, existem problemas interessantes, curiosos ou importantes, e cada um deles corresponde muitas vezes a uma pesquisa separada, que envolve opções de enfoque teórico, amostragem, coleta de dados e processamento, podendo estas ser únicas em relação às outras. O autor afirma ainda que saber o que está querendo descobrir é a primeira tarefa do pesquisador, mas ela não precisa necessariamente ocorrer no primeiro dia de trabalho.

\subsection{Incoerências Possíveis em um Problema de Pesquisa}

No que se refere a incoerências verificadas em problemas de pesquisa científica, constatam-se problemas que não são apresentados em forma interrogativa, o que constitui uma incoerência na sua formulação. Segundo Kerlinger (1980), o problema de pesquisa é uma questão, uma sentença em forma interrogativa, que geralmente pergunta algo a respeito das relações entre fenômenos ou variáveis, sendo sua resposta encontrada na pesquisa.

Outro possível problema na formulação de um problema é a incorporação de juízo de valor e problemas de engenharia. Gil (2009) afirma que a ciência não pode dar respostas a questões de "engenharia" e de valor, porque estas não são passíveis de verificação empírica. 
Um problema de pesquisa não pode estabelecer juízo de valor sobre o que é melhor ou pior em uma situação social (Richardson, 1999). Gressler (2003) apresenta o seguinte problema com juízo de valor: "Será o baixo rendimento escolar dos alunos consequência da má qualificação dos professores?". O autor afirma que pode ser, de certa forma, "aproveitado", porque está formulado de forma interrogativa e apresenta relação entre duas variáveis, porém precisa ser melhorado, de forma que não haja juízo de valor como, por exemplo: "Existe relação entre as notas dos alunos (aproveitamento escolar) do Ensino Fundamental e o grau de instrução dos professores?".

Kerlinger (1980) discute a questão de "engenharia", onde ressalta que uma questão de engenharia pergunta como fazer algo. Com respaldo no autor, Cunha, Magro e Dias apresentam, em seu estudo, uma questão que envolveu essa incoerência: "De que forma o uso do guidance por empresas concessionárias de serviços coletivos, como o de distribuição de gás natural, pode ser uma prática vantajosa para as partes interessadas"?

Outra inconsistência que pode ser verificada na formulação de problemas é a possibilidade de serem respondidos com "sim" ou "não". Cunha et al. (2012) asseveram que a busca por diferentes soluções requer que os problemas científicos não sejam respondidos com "sim" ou "não". Os autores afirmam que questionamentos como: "É possível que o docente influencie na formação do discente?" Fazem com que a pesquisa termine com uma resposta simples, de maneira que não há uma discussão sobre a pesquisa, o que possibilita a estagnação da ciência.

Diante das considerações apresentadas, pode-se afirmar que, além de ser um item inicial e essencial de um trabalho científico, o problema necessita, em sua formulação, muita atenção para não incorrer em nenhum erro que acarrete falta de clareza ou inconsistências que prejudiquem sua qualidade. 


\section{MÉTODOS DA PESQUISA}

As pesquisas descritivas têm como objetivo principal a descrição das características de determinada população ou fenômeno ou o estabelecimento de relações entre variáveis (Gil, 2009). Portanto, a metodologia utilizada quanto ao objetivo é descritiva porque descreve variáveis.

Em relação aos procedimentos, a pesquisa é caracterizada como bibliográfica, por analisar artigos científicos e desencadear em resultados por meio deles. De acordo com Raupp e Beuren (2012), esse tipo de pesquisa tem por objetivo a seleção, tratamento e interpretação de informação bruta, de modo que nestas possa ser incluído algum valor.

Quanto à abordagem do problema, a pesquisa é caracterizada como qualitativoquantitativa por utilizar-se de técnicas estatísticas para análise dos dados e, também, por analisar, de forma detalhada, os artigos e suas incoerências. Richardson (1999) afirma que a abordagem qualitativa é definida por descrever a complexidade de determinado problema, analisar a interação de certas variáveis, compreender e classificar processos dinâmicos vividos por grupos sociais, além de contribuir no processo de mudança de determinado grupo e possibilitar, com profundidade, a compreensão das particularidades do comportamento dos indivíduos. O autor ainda salienta que a abordagem quantitativa é marcada pelo uso de quantificação tanto nas modalidades de coletas de informações quanto no tratamento destas por meio de técnicas estatísticas, desde as mais simples até as mais complexas.

A população da pesquisa constituiu-se pelos 186 artigos do $22^{\circ}$ Congresso Brasileiro de Custos, e a amostra deu-se por meio de censo, ou seja, trabalhou-se com os 186 artigos. O evento aconteceu na cidade de Foz do Iguaçu/PR, entre os dias $11 \mathrm{e}$ 13 de novembro de 2015.

A coleta de dados ocorreu por meio dos Anais do Congresso, no qual os artigos encontram-se organizados pelas áreas temáticas: Abordagens Contemporâneas de Custos, Contribuições Teóricas para a Determinação e a Gestão de Custos, Custos Aplicados ao Setor Público, Custos Aplicados ao Setor Privado e Terceiro Setor, 
Problema de Pesquisa: Análise dos Artigos Científicos Publicados no 22 Congresso Brasileiro de Custos

Denize Cavichioli

Métodos Quantitativos Aplicados à Gestão de Custos, Custos como Ferramenta para o Planejamento, Controle e Apoio a Decisões e Metodologias de Ensino e Pesquisa em Custos.

Após a coleta, os artigos foram analisados por meio de estatística descritiva mediante o software Statistical Package for Social Sciences (SPSS), com a finalidade de calcular a frequência de artigos em cada área temática e as frequências de erros observados. Também utilizaram-se o software e o procedimento de correlação de Pearson para verificar se há relação entre o número de autores e as incoerências nos problemas de pesquisa, tendo sido verificadas as variáveis número de autores e as incoerências nos problemas de pesquisa. Nessa última variável, adotou-se o número 1 para artigos com incoerências e 0 para os artigos que não possuem incoerências nos problemas.

$\mathrm{Na}$ Tabela 1, a seguir, são apresentadas as áreas temáticas e seus respectivos números de artigos analisados em cada uma.

Tabela 1

\section{Número de Artigos por Área Temática}

\begin{tabular}{|c|c|c|}
\hline Área Temática & $\begin{array}{c}\text { Número de } \\
\text { Artigos }\end{array}$ & Frequência \\
\hline Abordagens Contemporâneas de Custos & 43 & $23,10 \%$ \\
\hline $\begin{array}{c}\text { Contribuições Teóricas para a Determinação e a Gestão de } \\
\text { Custos }\end{array}$ & 05 & $2,70 \%$ \\
\hline $\begin{array}{c}\text { Custos Aplicados ao Setor Público } \\
\text { Custos Aplicados ao Setor Privado e Terceiro Setor }\end{array}$ & 31 & $16,70 \%$ \\
\hline Métodos Quantitativos Aplicados à Gestão de Custos & 16 & $11,80 \%$ \\
\hline $\begin{array}{c}\text { Custos como Ferramenta para o Planejamento, Controle e } \\
\text { Apoio a Decisões }\end{array}$ & 57 & $3,60 \%$ \\
\hline Metodologias de Ensino e Pesquisa em Custos & 12 & $6,50 \%$ \\
\hline TOTAL & $\mathbf{1 8 6}$ & $\mathbf{1 0 0 , 0 0 \%}$ \\
\hline
\end{tabular}

Nota. Fonte: Anais do $22^{\circ}$ Congresso Brasileiro de Custos (2015).

Conforme pode ser observado na Tabela 1, a área temática que conta com o maior número de artigos é a de Custos como Ferramenta para o Planejamento, Controle e Apoio a Decisões, com 57 artigos, seguida da área Abordagens Contemporâneas de Custos, com 43. Já a que tem o menor número de artigos é a área 
Problema de Pesquisa: Análise dos Artigos Científicos Publicados no 22 Congresso Brasileiro de Custos

Denize Cavichioli

temática Contribuições Teóricas para a Determinação e a Gestão de Custos, com apenas 05 artigos.

Após observados os artigos separados por área temática, os mesmos foram tabulados em uma planilha eletrônica contendo o título do artigo, número e nome dos autores e problema de pesquisa. Para verificar o problema de pesquisa, foram analisados o resumo e a introdução de cada artigo, já que essas seções fazem menção ao item.

Com base na revisão da literatura, foi elaborado o constructo da pesquisa. Esse constructo pode ser visualizado no Quadro 2 a seguir. 
Problema de Pesquisa: Análise dos Artigos Científicos Publicados no 22 - Congresso Brasileiro de Custos

Denize Cavichioli

\begin{tabular}{|c|c|c|c|c|}
\hline Pesquisa & $\begin{array}{l}\text { Categoria } \\
\text { de Análise }\end{array}$ & Variáveis & Instrumentos/Questões & Autores \\
\hline \multirow[t]{7}{*}{ Qualitativa } & \multirow[t]{7}{*}{$\begin{array}{c}\text { Incoerência } \\
\text { nos } \\
\text { problemas } \\
\text { de } \\
\text { pesquisa }\end{array}$} & $\begin{array}{l}\text { Problema de } \\
\text { pesquisa na } \\
\text { introdução } \\
\text { ou resumo }\end{array}$ & $\begin{array}{c}\text { Existe problema de pesquisa } \\
\text { no resumo ou introdução? }\end{array}$ & $\begin{array}{l}\text { (Gressler, } \\
\text { 2003; Cunha } \\
\text { et al., 2012) }\end{array}$ \\
\hline & & $\begin{array}{l}\text { Explicitação } \\
\text { do problema } \\
\text { de pesquisa }\end{array}$ & $\begin{array}{c}\text { O problema de pesquisa está } \\
\text { explícito? }\end{array}$ & $\begin{array}{l}\text { (Gressler, } \\
\text { 2003; Cunha } \\
\text { et al., 2012) }\end{array}$ \\
\hline & & $\begin{array}{c}\text { Forma } \\
\text { Interrogativa }\end{array}$ & $\begin{array}{c}\text { O problema de pesquisa está } \\
\text { formulado na forma } \\
\text { interrogativa? }\end{array}$ & $\begin{array}{c}\text { (Gressler, } \\
\text { 2003; Cunha } \\
\text { et al., 2012) }\end{array}$ \\
\hline & & $\begin{array}{c}\text { Resposta } \\
\text { com "Sim" ou } \\
\text { "Não" }\end{array}$ & $\begin{array}{c}\text { O problema de pesquisa } \\
\text { pode ser respondido com } \\
\text { uma resposta do tipo "sim" } \\
\text { ou "não"? }\end{array}$ & $\begin{array}{l}\text { (Gressler, } \\
\text { 2003; Cunha } \\
\text { et al., 2012) }\end{array}$ \\
\hline & & $\begin{array}{l}\text { Problema de } \\
\text { Engenharia }\end{array}$ & $\begin{array}{l}\text { O problema de pesquisa } \\
\text { possui problema de } \\
\text { engenharia? }\end{array}$ & $\begin{array}{l}\text { (Gressler, } \\
\text { 2003; Cunha } \\
\text { et al., 2012) }\end{array}$ \\
\hline & & $\begin{array}{l}\text { Juízo de } \\
\text { Valor }\end{array}$ & $\begin{array}{l}\text { O problema de pesquisa } \\
\text { possui juízo de valor? }\end{array}$ & $\begin{array}{l}\text { (Gressler, } \\
\text { 2003; Cunha } \\
\text { et al., 2012) }\end{array}$ \\
\hline & & Metodologia & $\begin{array}{l}\text { A metodologia utilizada } \\
\text { responde corretamente ao } \\
\text { problema proposto? }\end{array}$ & $\begin{array}{l}\text { (Gressler, } \\
\text { 2003; Cunha } \\
\text { et al., 2012) }\end{array}$ \\
\hline Quantitativa & $\begin{array}{c}\text { Relação } \\
\text { entre o } \\
\text { número de } \\
\text { autores e a } \\
\text { qualidade } \\
\text { da } \\
\text { pesquisa }\end{array}$ & $\begin{array}{l}\text { Número de } \\
\text { Autores }\end{array}$ & $\begin{array}{l}\text { Existe relação entre o } \\
\text { número de autores e os } \\
\text { problemas por eles } \\
\text { apresentados? }\end{array}$ & $\begin{array}{c}\text { A autora } \\
(2017)\end{array}$ \\
\hline
\end{tabular}

\section{Quadro 2. Constructo da Pesquisa}

Fonte: A autora (2017). 


\section{ANÁLISE E DISCUSSÃO DOS RESULTADOS}

Nesta seção, são apresentados e discutidos os dados coletados junto aos artigos, sendo analisado seu problema. As análises foram orientadas pelo objetivo geral: verificar como foram elaborados e apresentados os problemas de pesquisa dos artigos científicos publicados no $22^{\circ}$ Congresso Brasileiro de Custos e a relação entre o número de autores e os problemas por eles apresentados. A seção é organizada de acordo com os itens expostos no Quadro 2.

\subsection{Explicitação do Problema de Pesquisa no Resumo ou na Introdução}

Dos artigos observados, destacam-se os que não explicitaram o problema de pesquisa no resumo ou na introdução. Com exatidão, dos 186 artigos aprovados no Congresso Brasileiro de Custos analisados, 51 não apresentaram o problema de forma explícita. Na Tabela 2, a seguir, são apresentados, por área temática, os artigos que não contêm tal elemento.

Tabela 2

Artigos que não apresentaram o problema no resumo ou introdução do artigo

\begin{tabular}{|l|c|c|}
\hline \multicolumn{1}{|c|}{ Área Temática } & $\begin{array}{c}\text { Número de } \\
\text { Artigos }\end{array}$ & $\begin{array}{c}\text { Frequência } \\
\text { em relação à } \\
\text { área temática }\end{array}$ \\
\hline Abordagens Contemporâneas de Custos & 6 & $13,33 \%$ \\
\hline $\begin{array}{l}\text { Contribuições Teóricas para a Determinação e a Gestão de } \\
\text { Custos }\end{array}$ & 1 & $20,00 \%$ \\
\hline Custos Aplicados ao Setor Público & 7 & $22,59 \%$ \\
\hline Custos Aplicados ao Setor Privado e Terceiro Setor & 10 & $45,46 \%$ \\
\hline Métodos Quantitativos Aplicados à Gestão de Custos & 5 & $31,25 \%$ \\
\hline $\begin{array}{l}\text { Custos como Ferramenta para o Planejamento, Controle e } \\
\text { Apoio a Decisões }\end{array}$ & 18 & $31,58 \%$ \\
\hline Metodologias de Ensino e Pesquisa em Custos & 4 & $33,33 \%$ \\
\hline TOTAL & $\mathbf{5 1}$ & $\mathbf{1 0 0 , 0 0 \%}$ \\
\hline
\end{tabular}

Nota. Fonte: Elaborado pela Autora (2017).

A partir da Tabela 2, é possível a verificação dos artigos que não apresentam problema de pesquisa, separados por área temática. Dos 51 artigos dessa categoria, o 
maior percentual de artigos sem problema em relação à sua área temática é demonstrado na área temática Custos Aplicados ao Setor Privado e Terceiro Setor, sendo $45,46 \%$. Já o menor percentual, de $13,33 \%$, é visto na área temática Abordagens Contemporâneas de Custos, ou seja, do total de artigos, 13,33\% não apresentam problema de pesquisa.

Cabe aqui ressaltar que, dos 186 artigos analisados, apenas 4 evidenciaram a apresentação do problema de pesquisa no resumo, sendo que, desses 4 , somente 1 repetiu o problema no resumo e na introdução; os outros três somente no resumo e não na introdução.

Tabela 3

Número de Artigos por Área Temática

\begin{tabular}{|c|c|c|}
\hline Área Temática & $\begin{array}{c}\text { Número de } \\
\text { Artigos }\end{array}$ & Frequência \\
\hline Abordagens Contemporâneas de Custos & 43 & $23,10 \%$ \\
\hline $\begin{array}{c}\text { Contribuições Teóricas para a Determinação e a Gestão de } \\
\text { Custos }\end{array}$ & 05 & $2,70 \%$ \\
\hline Custos Aplicados ao Setor Público & 31 & $16,70 \%$ \\
\hline Custos Aplicados ao Setor Privado e Terceiro Setor & 22 & $11,80 \%$ \\
\hline Métodos Quantitativos Aplicados à Gestão de Custos & 16 & $8,60 \%$ \\
\hline $\begin{array}{c}\text { Custos como Ferramenta para o Planejamento, Controle e } \\
\text { Apoio a Decisões }\end{array}$ & 57 & $30,60 \%$ \\
\hline Metodologias de Ensino e Pesquisa em Custos & 12 & $6,50 \%$ \\
\hline TOTAL & $\mathbf{1 8 6}$ & $\mathbf{1 0 0 , 0 0 \%}$ \\
\hline
\end{tabular}

Nota. Fonte: Anais do $22^{\circ}$ Congresso Brasileiro de Custos (2015).

A partir da Seção 4.2, são analisados somente os artigos que contêm problemas de pesquisa, eliminando-se da amostra os que não explicitam o problema de pesquisa, conforme exposto na Tabela 2. Sendo assim, na Tabela 4, são apresentados os 135 artigos a serem trabalhados, por área temática. 
Problema de Pesquisa: Análise dos Artigos Científicos Publicados no 22 - Congresso Brasileiro de Custos

Denize Cavichioli

Tabela 4

Artigos com problemas de pesquisa

\begin{tabular}{|c|c|c|}
\hline Área Temática & $\begin{array}{c}\text { Número de } \\
\text { Artigos }\end{array}$ & Frequência \\
\hline Abordagens Contemporâneas de Custos & 37 & $27,40 \%$ \\
\hline $\begin{array}{c}\text { Contribuições Teóricas para a Determinação e a Gestão } \\
\text { de Custos }\end{array}$ & 4 & $3,00 \%$ \\
\hline Custos Aplicados ao Setor Público & 24 & $17,80 \%$ \\
\hline Custos Aplicados ao Setor Privado e Terceiro Setor & 12 & $8,90 \%$ \\
\hline Métodos Quantitativos Aplicados à Gestão de Custos & 11 & $8,10 \%$ \\
\hline $\begin{array}{c}\text { Custos como Ferramenta para o Planejamento, Controle e } \\
\text { Apoio a Decisões }\end{array}$ & 39 & $28,90 \%$ \\
\hline Metodologias de Ensino e Pesquisa em Custos & 8 & $5,90 \%$ \\
\hline TOTAL & $\mathbf{1 3 5}$ & $\mathbf{1 0 0 , 0 0 \%}$ \\
\hline
\end{tabular}

Nota. Fonte: Elaborado pela Autora (2017).

Dessa forma, para análise dos problemas nas próximas seções, de acordo com a Tabela 4, são considerados 135 artigos, sendo 37 da área temática Abordagens Contemporâneas de Custos, 4 da área Contribuições Teóricas para a Determinação e a Gestão de Custos, 24 de Custos Aplicados ao Setor Público, 12 de Custos Aplicados ao Setor Privado e Terceiro Setor, 11 de Métodos Quantitativos Aplicados à Gestão de Custos, 39 de Custos como Ferramenta para o Planejamento, e 8 de Controle e Apoio a Decisões e Metodologias de Ensino e Pesquisa em Custos.

\subsection{Problema Formulado na Forma Interrogativa}

Conforme apresentado na literatura, o problema deve ser enunciado na forma de pergunta, pois, de acordo com Marconi e Lakatos (2013), essa é uma das questões que o problema deve atender. Dessa forma, nessa seção, foram verificados, nos 135 analisados, quantos apresentaram o problema na forma interrogativa. Gressler (2003) apresenta um exemplo de questão de pesquisa: "Qual a influência da recompensa sobre a aprendizagem?"

Dos 135 artigos analisados, foram identificados 4 que não apresentaram o problema na forma interrogativa, sendo 3 na área temática Abordagens Contemporâneas de Custos e 1 na área temática Contribuições Teóricas para a Determinação e a Gestão de Custos. Tal resultado é semelhante ao encontrado por 
Cunha et al. (2012), que encontraram, em um total de 98 artigos aprovados no $11^{\circ}$ Congresso USP de Controladoria e Contabilidade, 2 artigos que não apresentaram o problema de pesquisa na forma interrogativa. Os problemas sem interrogação são explanados a seguir:

a) "A problemática que se coloca aos pesquisadores e interessados no assunto, a partir das considerações supracitadas, é verificar como se dá a aplicação simultânea e inter-relacionada entre a Gestão Interorganizacional de Custos (GIC) e o consórcio modular, e qual a eficácia das estratégias de cooperação para a competição e a redução dos custos globais das operações, no contexto da indústria automobilística";

b) "Este artigo propõe uma nova metodologia para calcular o êxito de um clube de futebol dado seu nível de gastos, ou seja, uma nova forma de calcular a eficiência dos gastos";

c) "O problema que este estudo se propõe a analisar pauta-se no fato de que as empresas, ao desconhecerem que o excesso de controle acionário representa uma medida de risco perante as instituições financeiras, podem deixar de adotar medidas que amenizem a causa destes custos de agência da dívida";

d) "A questão problema que orienta esse estudo nos leva a algumas reflexões: As bolsas de fomento a estudos nos programas de Mestrado e Doutorado são suficientes para custear todas as despesas dos discentes bolsistas durante 0 curso, bem como quais os critérios adotados pelos bolsistas na aplicação desse recurso".

O problema de pesquisa deve ser claramente elaborado, de forma interrogativa, para que se possa buscar uma resposta no decorrer da pesquisa e haja sua explanação nos resultados e nas considerações finais. Além disso, o fato de formular um problema na forma interrogativa facilita a visualização da pesquisa e demonstra que ainda não há uma resposta sobre determinado assunto, o que torna a pesquisa relevante. 
Problema de Pesquisa: Análise dos Artigos Científicos Publicados no 22 Congresso Brasileiro de Custos

Denize Cavichioli

\subsection{Problema Respondido com "Sim" ou "Não"}

Salientam-se artigos analisados que possuem problema com a possibilidade de serem respondidos com "sim" ou "não". Para responder esses problemas, não há necessidade de uma discussão tão profunda, o que pode prejudicar a qualidade de sua resolução. Na Tabela 5, são apresentados os artigos com essa incoerência, separados por área temática.

Tabela 5

Artigos que podem ser respondidos com "Sim" ou "Não"

\begin{tabular}{|c|c|c|}
\hline Área Temática & $\begin{array}{c}\text { Número de } \\
\text { Artigos }\end{array}$ & Frequência \\
\hline Abordagens Contemporâneas de Custos & 5 & $27,80 \%$ \\
\hline Custos Aplicados ao Setor Público & 5 & $27,80 \%$ \\
\hline Métodos Quantitativos Aplicados à Gestão de Custos & 2 & $11,10 \%$ \\
\hline $\begin{array}{c}\text { Custos como Ferramenta para o Planejamento, Controle e } \\
\text { Apoio a Decisões }\end{array}$ & 6 & $33,30 \%$ \\
\hline TOTAL & $\mathbf{1 8}$ & $\mathbf{1 0 0 , 0 0 \%}$ \\
\hline
\end{tabular}

Nota. Fonte: Elaborado pela Autora (2017).

Como pode ser observado na Tabela 5, 18 dos artigos analisados apresentam problemas que podem ser respondidos com "sim" ou "não". Em sua pesquisa, Cunha et al. (2012) também encontraram 18 artigos que podem ser respondidos com simples "sim" ou "não". A área temática com mais artigos contendo essa inconsistência foi a área Custos como Ferramenta para o Planejamento, Controle e Apoio a Decisões, enquanto as áreas Contribuições Teóricas para a Determinação e a Gestão de Custos e Metodologias de Ensino e Pesquisa em Custos não apresentaram essa incoerência.

Exemplos de problemas que podem ser respondidos com "sim" ou "não" verificados foram os seguintes: "Existe diferença na relevância da informação contábil entre os países que compõem os BRICS e EUA?"; "Há diferenças de estimação do custo médio ponderado de capital ao utilizar os juros da remuneração de capitais de terceiros presentes na DVA em detrimento das despesas financeiras da DRE?"; "As empresas que compõem o Índice de Sustentabilidade Empresarial (ISE) evidenciam os indicadores socioambientais conforme as diretrizes do GRI?"; "Existe diferença na 
eficiência da gestão econômico-financeira entre os hospitais filantrópicos, públicos e privados?"; e "A implantação de um sistema de custos efetivamente ajuda e moderniza a administração dos serviços dos Conselhos de Fiscalização Profissional?".

O fato de os problemas serem respondidos com "sim" ou "não" diminui as discussões que podem ocorrer durante a pesquisa, de maneira a explorar uma resposta, visto que se busca uma resposta relativamente "curta".

No problema "A implantação de um sistema de custos efetivamente ajuda e moderniza a administração dos serviços dos Conselhos de Fiscalização Profissional?" Por exemplo, uma maneira de engrandecer a discussão em torno de sua resposta seria "Como a implantação de um sistema de custos efetivamente ajuda e moderniza a administração dos serviços dos Conselhos de Fiscalização Profissional?" Para esse problema reformulado, poderia haver discussões maiores e possíveis várias respostas, por meio de uma pesquisa de cunho qualitativo.

\subsection{Problemas de "Engenharia" e Juízo de Valor}

Problemas de "Engenharia" e Juízo de Valor são inconsistências, conforme abordado na literatura por Gil (2009). Com relação a problemas contendo juízo de valor, não foram encontrados, na amostra de artigos analisados, problemas com essa inconsistência.

No que se refere a problemas de "engenharia", na Tabela 6 são visualizados os artigos que os contêm, separados por área temática.

Tabela 6

Artigos com problema de engenharia

\begin{tabular}{|c|c|c|}
\hline Área Temática & $\begin{array}{c}\text { Número de } \\
\text { Artigos }\end{array}$ & Frequência \\
\hline Custos Aplicados ao Setor Privado e Terceiro Setor & 1 & $14,30 \%$ \\
\hline Custos Aplicados ao Setor Público & 3 & $42,90 \%$ \\
\hline Métodos Quantitativos Aplicados à Gestão de Custos & 1 & $14,30 \%$ \\
\hline $\begin{array}{c}\text { Custos como Ferramenta para o Planejamento, Controle e } \\
\text { Apoio a Decisões }\end{array}$ & 2 & $28,60 \%$ \\
\hline TOTAL & $\mathbf{7}$ & $\mathbf{1 0 0 , 0 0 \%}$ \\
\hline
\end{tabular}

Nota. Fonte: Elaborado pela Autora (2017). 
De acordo com a Tabela 6, 7 artigos apresentaram problemas de "engenharia". $\mathrm{Na}$ área temática Custos Aplicados ao Setor Privado e Terceiro Setor, o problema com "engenharia" encontrado foi o seguinte: "De que forma cada uma das três espécies de Custeio por Absorção pode auxiliar nas necessidades dos produtores rurais quanto à mensuração dos custos no cultivo da soja?". Já na área temática Custos Aplicados ao Setor Público, destacam-se os seguintes: "Quais as oportunidades de melhorias na gestão do capital intelectual das Diretorias de Planejamento e Administração dos Campi do Instituto Federal do Paraná (IFPR)?"; "A implantação de um sistema de custos efetivamente ajuda e moderniza a administração dos serviços dos Conselhos de Fiscalização Profissional?"; "Qual o modelo de sistema de informação de custos adequado a ser adotado na administração pública municipal de Itaguari?"; "Como a análise do ciclo de vida do produto e a classificação de clientes podem contribuir para que o comércio varejista de calçados e acessórios possa planejar estratégias de venda de seus produtos para melhor gerir os seus resultados?"

$\mathrm{Na}$ área temática Métodos Quantitativos Aplicados à Gestão de Custos, a questão dúbia de engenharia foi encontrada no problema: "Como o novo modelo de previsão de insolvência pode contribuir na prevenção de custos de falência em empresas de capital aberto?" Ainda, na área temática Custos como Ferramenta para o Planejamento, Controle e Apoio a Decisões, foram encontradas inconsistências nos seguintes problemas: "Como a análise do ciclo de vida do produto e a classificação de clientes podem contribuir para que o comércio varejista de calçados e acessórios possa planejar estratégias de venda de seus produtos para melhor gerir os seus resultados?"; e "Como melhorar a informação da contribuição do objeto de custo à formação do resultado no Custeio Variável quando na estrutura de gastos se tem de forma representativa a presença de gastos fixos próprios?"

Os problemas de engenharia e de juízo de valor denotam certo viés por parte do pesquisador, fazendo com que este suponha o que é melhor ou pior, bom ou ruim, etc. Portanto, expressões como "melhor" e outras do gênero devem ser evitadas.

Exemplo: "Como a análise do ciclo de vida do produto e a classificação de clientes podem contribuir para que um comércio varejista de calçados e acessórios 
Problema de Pesquisa: Análise dos Artigos Científicos Publicados no 22 Congresso Brasileiro de Custos

Denize Cavichioli

possa planejar estratégias de venda de seus produtos para melhor gerir os seus resultados?" Aqui pode ser retirada a palavra "melhor", ficando reescrito da seguinte forma: "Como a análise do ciclo de vida do produto e a classificação de clientes podem contribuir para que um comércio varejista de calçados e acessórios possa planejar estratégias de venda de seus produtos para gerir os seus resultados?"

\subsection{Resumo das Inconsistências Verificadas em Cada Área Temática}

De maneira a sintetizar os resultados obtidos em cada item de verificação do constructo, a seguir, na Tabela 7, são expostas as inconsistências encontradas nos problemas dos artigos científicos em cada área temática do Congresso. 
Problema de Pesquisa: Análise dos Artigos Científicos Publicados no 22 - Congresso Brasileiro de Custos

Denize Cavichioli

Tabela 7

Resumo das Inconsistências por Área Temática

\begin{tabular}{|c|c|c|c|c|c|}
\hline Área Temática & $\begin{array}{c}\text { Falta de } \\
\text { Explicitação } \\
\text { do } \\
\text { Problema. }\end{array}$ & $\begin{array}{c}\text { Problema não } \\
\text { apresentado } \\
\text { na forma } \\
\text { interrogativa. }\end{array}$ & $\begin{array}{c}\text { Problema } \\
\text { possível de ser } \\
\text { respondido } \\
\text { com "sim" ou } \\
\text { "não". }\end{array}$ & $\begin{array}{l}\text { Problema de } \\
\text { “engenharia". }\end{array}$ & TOTAL \\
\hline $\begin{array}{l}\text { Abordagens } \\
\text { contemporâneas } \\
\text { de Custos }\end{array}$ & 6 & 3 & 5 & 0 & 14 \\
\hline $\begin{array}{l}\text { Contribuições } \\
\text { Teóricas para a } \\
\text { Determinação e a } \\
\text { Gestão de Custos }\end{array}$ & 1 & 1 & 0 & 0 & 2 \\
\hline $\begin{array}{l}\text { Custos Aplicados } \\
\text { ao Setor Público }\end{array}$ & 7 & 0 & 5 & 3 & 15 \\
\hline $\begin{array}{l}\text { Custos Aplicados } \\
\text { ao Setor Privado e } \\
\text { Terceiro Setor }\end{array}$ & 10 & 0 & 0 & 1 & 11 \\
\hline $\begin{array}{l}\text { Métodos } \\
\text { Quantitativos } \\
\text { Aplicados à } \\
\text { Gestão de Custos }\end{array}$ & 5 & 0 & 2 & 1 & 8 \\
\hline $\begin{array}{l}\text { Custos como } \\
\text { Ferramenta para o } \\
\text { Planejamento, } \\
\text { Controle e Apoio a } \\
\text { Decisões }\end{array}$ & 18 & 0 & 6 & 2 & 26 \\
\hline $\begin{array}{l}\text { Metodologias de } \\
\text { Ensino e Pesquisa } \\
\text { em Custos }\end{array}$ & 4 & 0 & 0 & 0 & 4 \\
\hline TOTAL & 51 & 4 & 18 & 7 & 80 \\
\hline
\end{tabular}

Nota. Fonte: Elaborado pela Autora (2017).

Por intermédio da Tabela 7, observa-se que foram verificadas 80 inconsistências nos problemas dos artigos científicos do $22^{\circ}$ Congresso Brasileiro de Custos, sendo que a maior quantidade foi observada na área temática Custos como Ferramenta para 0 Planejamento, Controle e Apoio a Decisões, com 26 inconsistências no total. 
Problema de Pesquisa: Análise dos Artigos Científicos Publicados no 22 ํㅡㄹ Congresso Brasileiro de Custos

Denize Cavichioli

\subsection{Relação entre o Número de Autores e Problemas de Pesquisa com Incoerências}

Com o intuito de verificar se existe relação entre o número de autores e a qualidade do problema de pesquisa, primeiramente, apresenta-se, na Tabela 8, o número de autores dos artigos com incoerências em seu problema de pesquisa.

Tabela 8

Número de Autores dos Artigos com Inconsistências

\begin{tabular}{|c|c|c|}
\hline Número de Autores & Número de Artigos & Frequência \\
\hline 01 & 07 & $8,80 \%$ \\
\hline 02 & 12 & $15,00 \%$ \\
\hline 03 & 28 & $35,00 \%$ \\
\hline 04 & 17 & $21,30 \%$ \\
\hline 05 & 06 & $7,50 \%$ \\
\hline 06 & 10 & $12,50 \%$ \\
\hline TOTAL & $\mathbf{8 0}$ & $\mathbf{1 0 0 , 0 0} \%$ \\
\hline
\end{tabular}

Nota. Fonte: Elaborado pela Autora (2017).

De acordo com a Tabela 8 , dos 80 artigos com inconsistências, o número de autores com maior percentual verificado foi de 03 autores, com um percentual de $35,00 \%$, seguido de 04 autores, com um percentual de $21,30 \%$.

$\mathrm{Na}$ Tabela 9 a seguir, são apresentados os resultados da correlação de Pearson entre o número de autores e os problemas com inconsistências.

Tabela 9

Coeficiente de correlações de Pearson entre as variáveis número de autores e problemas da pesquisa com incoerências $(\mathrm{N}=186)$

\begin{tabular}{|c|c|c|}
\hline & Autores & Problemas com Inconsistências \\
\hline Autores & 1 & \\
\hline Problemas com Inconsistências & 0,054 & 1 \\
\hline
\end{tabular}

Nota. Fonte: Elaborado pela autora (2017).

$\mathrm{N}=$ Amostra; * $=$ Nível de significância de 0,$05 ;{ }^{* *}$ Nível de significância de 0,01 
Conforme pode ser observado na Tabela 9, não foi encontrada relação estatisticamente significativa entre o número de autores e problemas de pesquisa com incoerências. No que concerne à qualidade de elaboração de artigos, tal resultado diverge do encontrado por Rodríguez-Ruiz e Fernández-Menéndez (2009) de que, quanto maior o número de autores de uma publicação, tanto maior é a rede de colegas que podem potencialmente citá-la, fato que evidencia qualidade.

Dessa forma, infere-se que o número de autores não interfere na qualidade do problema de pesquisa.

\section{CONSIDERAÇÕES FINAIS}

A seguinte questão orientou a pesquisa: Como foram elaborados e apresentados os problemas de pesquisa dos artigos científicos publicados no $22^{\circ}$ Congresso Brasileiro de Custos e qual a relação entre o número de autores e os problemas por eles apresentados? Para responder tal indagação, foram coletados os artigos dos anais do respectivo congresso e analisados, de maneira individual, seus problemas de pesquisa.

Os problemas foram analisados com base no que foi apresentado na teoria, no que tange à sua explicitação no resumo ou na introdução, se são apresentados na forma interrogativa, se há possibilidade de respondê-los com "sim" ou "não" e se têm problema de "engenharia" ou juízo de valor em sua formulação.

O estudo mostrou, inicialmente, que dos 186 artigos analisados, 51 deles não apresentaram problema de pesquisa de forma explícita, o que resultou em uma amostra de 136 artigos para análise de inconsistências em suas formulações. Tal fato merece destaque em razão de o congresso ter sido classificado como $\mathrm{E} 1$ pela área da Administração, Ciências Contábeis e Turismo da CAPES (CBC, 2017).

Com relação ao fato de o problema não ser apresentado na forma interrogativa, de ter possibilidade de ser respondido com "sim" ou "não" e apresentar problema de "engenharia", foram encontradas respectivamente 4, 18 e 7 incoerências. 
Constatou-se que a área temática Custos como Ferramenta para o Planejamento, Controle e Apoio a Decisões, com o maior número de artigos aprovados, 57 , também foi a que mais apresentou inconsistências na formulação de problemas, equivalendo a um número de 26.

Além disso, as incoerências mais recorrentes foram a não explicitação do problema de pesquisa no resumo e na introdução, com um número de 51 , e a possibilidade de o mesmo ser respondido com "sim" ou "não", que incorreu em um número de 18.

Ainda, no que se refere ao número de autores e problemas de pesquisa com incoerências, não foi encontrada relação estatisticamente significativa que comprove tal relação.

Dessa forma, responde-se a questão da pesquisa, concluindo-se, de maneira geral, que há baixa qualidade na elaboração e apresentação dos problemas de pesquisa dos artigos científicos publicados no $22^{\circ}$ Congresso Brasileiro de Custos e que não há relação entre o número de autores e os problemas por eles apresentados. Com a ocorrência de 80 inconsistências na apresentação dos problemas de pesquisa, questiona-se o rigor com que os avaliadores tratam os artigos enviados para submissão.

Diante de tais considerações, os autores precisam observar os elementos básicos da composição de um problema, de forma que possam aprofundar suas discussões por meio da pesquisa científica e proporcionar aos leitores uma leitura clara do que se busca alcançar com os estudos.

Como contribuição teórica do estudo, destaca-se a apresentação de incoerências em problemas de pesquisa, que podem ser evitados e que comprometem a qualidade de uma pesquisa. Tratando-se de contribuição acadêmica, o estudo buscou contribuir para a pesquisa em Contabilidade.

Como limitação, o estudo apresenta o fato de que foram pesquisados somente os anais do $22^{\circ}$ Congresso Brasileiro de Custos, visto que investigar outras edições dificultaria um aprofundamento e apresentação individual dos problemas de pesquisa. Tal limitação impossibilita a verificação das possíveis inconsistências em outras edições 
do congresso. Consoante isso, sugere-se que sejam realizadas pesquisas futuras nas outras edições do referido congresso e também em outros eventos da área de contabilidade, de forma que possa haver comparação dos resultados.

\section{REFERÊNCIAS}

Beuren, I. M. (2012). Como elaborar trabalhos monográficos em contabilidade: teoria e prática. São Paulo: Atlas.

Blaikie, N. (2009). Designing social research. Polity.

Castro, C. M. (2006). A prática da pesquisa. São Paulo: Pearson Prentice Hall.

CBC (2017). XXIV Congresso Brasileiro de Custos. Recuperado de: <http://cbc2017.abcustos.org.br/apresentacao/>.

Cunha, P. R., Dal Magro, C. B., \& Dias, D. R. (2012). Análise do problema de pesquisa dos artigos científicos publicados no 11. Congresso USP de Controladoria e Contabilidade. Revista de Contabilidade e Organizações, 6(15), 123.

Gil, A. C. (2009). Métodos e técnicas de pesquisa social. São Paulo: Atlas.

Gomides, J. E. (2002). A definição do Problema de Pesquisa: a chave para o sucesso do Projeto de Pesquisa. Revista do Centro de Ensino Superior de Catalão-CESUCAno IV, (6).

Gressler, L. A. (2003). Introdução à pesquisa: projetos e relatórios. São Paulo: Loyola.

Johnson, B., \& Christensen, L. (2008). Educational research: Quantitative, qualitative, and mixed approaches. Sage.

Kerlinger, F. N. (1980). Metodologia da pesquisa em ciências sociais. São Paulo: EPU.

Marconi, M. A., \& Lakatos, E. M. (2013). Metodologia do Trabalho Científico. São Paulo: Atlas.

Nascimento, A. S., Aragão, I. R. B. N., Gomes, C. A. S., \& Nova, S. P. D. C. C. (2013). Pesquisa Científica e a Construção do Conhecimento: Possibilidade e Prática ou Utopia? Revista Evidenciação Contábil \& Finanças, 1(2), 106-122. 
Raupp, F. M., \& Beuren, I. M. (2012). Metodologia da pesquisa aplicável às ciências sociais. In: Beuren, I. M. Como elaborar trabalhos monográficos em contabilidade: teoria e prática. São Paulo: Atlas, 76-96.

Richardson, R. J. (1999). Pesquisa social: métodos e técnicas. São Paulo: Atlas.

Rodríguez-Ruiz, Ó., \& Fernández-Menéndez, J. (2009). Intellectual capital revisited: a citation analysis of ten years of research in the area (1997-2007). Management Research: Journal of the Iberoamerican Academy of Management, 7(3), 203-219.

Silva, S. C., Araújo, K. D., Zuccolotto, R., \& Pinto, M. R. (2013). Análise Epistemológica das Propriedades Fundamentais do Problema, Objetivos e Hipóteses de Artigos nos Congressos USP e ENANPAD. Revista Universo Contábil, 9(4).

Data de Submissão: 27/12/2016

Data de Aceite: 16/01/2018 